\title{
COMUNIDADES \\ TRADICIONAIS E PRECONCEITO: SUBSÍDIOS PARA A FORMAÇÃO DE PROFESSORES
}

TRADITIONAL COMMUNITIES AND PREJUDICE: SUBSIDIES FOR TEACHER TRAINING

COMUNIDADES TRADICIONALES Y PREJUICIO: SUBVENCIONES PARA LA FORMACIÓN DEL PROFESORADO

Fábio Fernandes Villela

Doutor em Sociologia pela UNICAMP. Docente da Universidade Estadual Paulista Júlio de Mesquita Filho (UNESP) - São José do Rio Preto - SP - Brasil.

Resumo: Este texto tem por objetivo apresentar os resultados da pesquisa que possibilitou investigar as representações sociais do preconceito contra a origem geográfica e de lugar em alunos de escolas de meio rural, com a finalidade principal de aprimorar a formação de professores (Cf. Autor, 2013-2015). No contexto da macrorregião de São José do Rio Preto (SP), são relevantes as representações sociais sobre os "caipiras", de modo que este projeto colabora na elaboração de pesquisas interessadas na descrição e na compreensão de processos 
envolvendo relações entre o preconceito, a educação e o mundo rural, especialmente das comunidades tradicionais denominadas "caipiras". Esta pesquisa possibilitou, com relação à formação de professores, problematizar a perspectiva da contra-hegemonia cultural; inferir que se deve trabalhar o preconceito contra a origem geográfica e de lugar como elemento de constituição da humanização do educando; e teorizar a formação na perspectiva da ação política voltada para a transformação social.

Palavras-chave: Comunidades Tradicionais. Representações Sociais. Preconceito contra a Origem Geográfica e de Lugar. Bullying Escolar. Formação de Professores.

Abstract: This text presents the results of a study to investigate the social representations of prejudice against geographical origin and place in students from rural schools, with the main purpose of improving teacher training (cf. Author, 2013-2015). In the context of the macro-region of São José do Rio Preto (SP), social representations of the "caipiras" (which can be translated as yokels, or country bumpkins) are very relevant; therefore, this project collaborates in the development of research aimed at describing and understanding the processes involving the relations between prejudice, education, and the rural world, especially traditional communities known as "caipiras". In relation to teacher training, this research investigates the perspective of cultural counterhegemony; it to infer that prejudice against geographical origin and place needs to be seen as an element in the formation of humanity of the student; and it theorizes about training from the perspective of political action aimed at social transformation. 
Keywords: Traditional Communities. Social Representations. Prejudice against Geographic Origin and Place. School Bullying. Teacher Training.

Resumen: Este texto tiene como objetivo presentar los resultados de la investigación que ha permitido profundizar el estudio de las representaciones sociales de los prejuicios contra el origen geográfico y el lugar en los estudiantes de las escuelas rurales, con el objetivo principal de mejorar la formación del profesorado (cf. Autor, 2013-2015). En el contexto de la macrorregión de São José do Rio Preto (SP), son relevantes las representaciones sociales acerca de los "paletos". El objetivo de este proyecto es colaborar en el desarrollo delas investigaciones pertinentes en la descripción y comprensión de los procesos que implican relaciones entre el prejuicio, la educación y el mundo rural, especialmente en las comunidades tradicionales denominadas "paletos". Esta investigación permitió, con respecto a la formación del profesorado, discutir la perspectiva de contra-hegemonía cultural; inferir que se debe trabajar sobre los prejuicios contra el origen geográfico y de lugar como un elemento de constitución de la humanización del estudiante; y teorizar la formación desde la perspectiva de la acción política dirigida a los cambios sociales.

Palabras clave: Comunidades Tradicionales. Representaciones Sociales. Prejuicio contra el Origen Geográfico y el Lugar. Acoso Escolar. Formación del Profesorado.

INTRODUÇÃO

ste texto tem por objetivo apresentar os resultados da pesquisa intitulada: Novas ruralidades e mundo do trabalho: estudo das representações sociais de jovens de escolas de meio rural através 
do uso de mídias sociais (Cf. Autor, 2013-2015). Esse trabalho possibilitou investigar as representações sociais do preconceito contra a origem geográfica e de lugar em alunos do Ensino Médio de escolas de meio rural, para a formação de professores. Estudar as representações sociais do preconceito contra a origem geográfica e de lugar possibilita pensar a formação de professores numa perspectiva de contra-hegemonia cultural. No contexto da macrorregião de São José do Rio Preto, são relevantes as representações sociais dos "caipiras", de modo que este projeto vem colaborar na elaboração de pesquisas interessadas na descrição e na compreensão de processos que envolvem relações entre o preconceito, a educação e o mundo rural, especialmente das comunidades tradicionais denominadas "caipiras". Este texto está organizado da seguinte maneira: (1) objeto e objetivos; (2) fundamentação teórica; (3) metodologia e análise dos resultados; (4) conclusões; e (5) referências.

\section{OBJETO E OBJETIVOS}

Este projeto tem por objeto e objetivos estudar as representações sociais do preconceito contra a origem geográfica e de lugar em alunos do Ensino Médio de escolas do meio rural, para a formação de professores e, por desdobramento, estudar as comunidades denominadas "tradicionais", nas quais estão inseridos esses jovens. "Comunidades tradicionais" é um conceito explicitado na Política Nacional de Desenvolvimento Sustentável dos Povos e Comunidades Tradicionais (PNPCT) em seu artigo terceiro. São grupos culturalmente diferenciados que possuem formas próprias de organização social, que ocupam e usam territórios e recursos naturais como condição para sua reprodução cultural, social, religiosa, ancestral e econômica, utilizando conhecimentos, inovações e práticas gerados e transmitidos pela tradição (BRASIL, 2007).

Considerando os diferentes contextos geográficos e as peculiaridades culturais que envolvem essas comunidades, Diegues (1999) listou 16 populações tradicionais "não indígenas" brasileiras, dentre elas, os "caipiras ou sitiantes": comunidades, em grande parte de meeiros e parceiros, que sobrevivem em nichos entre as monoculturas do Sudeste e do Centro-Oeste, desenvolvendo atividades agropecuárias em pequenas propriedades, destinadas à subsistência familiar e ao mercado. Diegues (1999, p. 40), distingue as seguintes populações tradicionais não indígenas: caiçaras, caipiras, babaçueiros, jangadeiros, pantaneiros, 
pastoreios, praieiros, quilombolas, caboclos/ribeirinhos amazônicos, ribeirinhos não amazônicos, varjeiros, sitiantes, pescadores, açorianos, sertanejos/vaqueiros. Diegues (1999, p. 52) caracteriza os caipiras:

Os caipiras são hoje, em grande parte, sitiantes, meeiros e parceiros que sobrevivem precariamente em nichos entre as monoculturas do Sudeste e Centro-Oeste, em pequenas propriedades em que desenvolvem atividades agrícolas e de pequena pecuária, cuja produção se dirige para a subsistência familiar e para o mercado. (DIEGUES, 1999, p. 52).

O autor indica em um mapa a localização aproximada do território dessas populações, salientando que, no caso dos caipiras, restam somente alguns enclaves onde elas subsistem. Diegues (1999, p. 40) ressalta que: "não existe uma linha muito definida que separe os territórios dessas populações, ocorrendo mesmo nichos de algumas delas espalhados em áreas fora de suas regiões originais". A partir dessa peculiaridade cultural, foram selecionadas duas escolas parceiras, de "meio rural", nas quais se desenvolveu a pesquisa.

Essa pesquisa possibilitou vislumbrar meios de aprimoramento das atividades de formação de professores e gestores a partir do diálogo feito com os alunos participantes da pesquisa. Articula ensino e pesquisa, pois a atuação nas escolas públicas estaduais de meio rural, por meio de aplicação de atividades de ensinoaprendizagem, sob coordenação de docente da universidade, gera: (a) reflexão sobre o ensino, quer na esfera da universidade, quer na esfera do Ensino Médio; e (b) dados para o projeto trienal de pesquisa (Autor, 2013-2015). Possibilita também uma formação diferenciada ao aluno de pedagogia, por ganhar experiência em lidar com a complexidade da sala de aula no cotidiano da escola e, assim, desenvolver pesquisa e reflexão sobre a formação curricular frente aos desafios de atuar no mercado de trabalho. Por fim, vislumbra soluções de políticas públicas mais eficientes e eficazes para o Ensino Médio.

\section{FUNDAMENTAÇÃO TEÓRICA}

Há uma grande diversidade de concepções sobre a questão das representações sociais. Nossa abordagem teórico-metodológica parte da teoria das representações de Lefebvre (2006). Para Lefebvre (2006), as representações são um produto de um determinado processo social e histórico e podem ser desveladas por meio da reflexão e da relação com as condições de vida 
daqueles que as produzem. Conforme aponta Lutfi et al. (1996), ao estudar as representações (p. ex., de jovens, em nossa pesquisa) em determinado contexto social, é necessário levar em consideração as condições de vida dos grupos ou das classes sociais que as produzem.

Para Almeida (2001), as representações sociais dos alunos em relação a determinado saber são o ponto de partida (saber imediato); e as sínteses cognitivas, elaboradas pelos alunos, o ponto de chegada (saber mediato). Para o autor, as contradições desses termos provocam tensões nas representações do aluno (saber imediato), que podem gerar a superação do imediato no mediato pretendido, possibilitando, assim, a elaboração de sínteses, a aprendizagem. Novas relações pedagógicas têm como ponto de partida as representações sociais imediatas dos alunos em relação a determinado saber e, como ponto de chegada, a superação do imediato no mediato.

O conceito de representações sociais, segundo Almeida (2001, p. 151), está assentado numa visão ontológica, cujas representações se prestam à manutenção das relações sociais vigentes e são tanto mais eficientes no desempenho desta atribuição quanto maior for sua aparente criticidade. As representações são, na verdade, ideologia dominante, apresentam ideias que não expressam o real, mas a aparência social, uma imagem das coisas, dos homens. O autor trabalha o conceito de representação como uma distorção da realidade.

O trabalho educativo, segundo Almeida (2001), potencializa transformações nas representações sociais dos alunos, possibilitando-Ihes alcançar outro patamar do saber mediato. Potencializar significa relativizar a ação educativa escolar, entendendo-a articulada a outras ações educativas que compõem o mundo natural e humano social, implicando a transformação de um pensamento linear.

Considera-se como um trabalho de referência o estudo feito por Silva (2006), no qual o autor se propõe a captar as representações das crianças de meio rural, que frequentavam pequenas escolas do concelho (sic) de Ponte de Lima, sobre o mundo do trabalho. Outro trabalho importante é o de Lopes (2008), cujo autor objetivou estudar as representações sociais dos jovens do campo acerca de suas escolas no município de Bragança, no estado do Pará. A questão central desse trabalho foi analisar as formas pelas quais acontecem interferências dessas representações sociais dos jovens do campo, acerca de suas escolas, para com as práticas de inclusãoexclusão da ação educativa desencadeada nas escolas no campo. 
Uma das representações sociais que emergem de nossa pesquisa é o preconceito contra a origem geográfica e de lugar, especialmente com relação aos alunos de meio rural, denominados "caipiras". Segundo Albuquerque Júnior (2007), este tipo de preconceito é justamente aquele que marca alguém pelo simples fato deste pertencer ou advir de um território, espaço, lugar, vila, cidade, província, estado, região, nação, país, continente, considerado por outro ou outro quase sempre mais poderoso ou poderosa, como sendo inferior, rústico, bárbaro, selvagem, atrasado, subdesenvolvido, menor, menos civilizado, feio, ignorante, culturalmente inferior, etc.

O preconceito contra a origem geográfica e de lugar possui "afinidade eletiva" (Cf. Löwy, 1989) com o preconceito denominado "anti-Mezzogiorno" por Gramsci [1927 (1987)] em seu último trabalho em liberdade: "Alguns temas sobre a questão meridional". Esse texto permite repensar a teoria da hegemonia sobre as classes subalternas contemporaneamente. Segundo Kohan (2007), nesse trabalho de Gramsci está resumida grande parte de seus programas de investigações carcerárias, os quais ele começa a explorar, dois anos e quatro meses após ser aprisionado, especialmente o preconceito de origem e de lugar difundido nas escolas, associado à teoria da hegemonia sobre as classes subalternas. Para Kohan (2007, p. 53-54), nesse texto, Gramsci

[...] formula o núcleo central da teoria da hegemonia (dominação sobre os capitalistas e direção sobre os camponeses). De igual modo, formula-se aí uma das primeiras reflexões explícitas acerca da importância das instituições da sociedade civil [...] e seu papel hegemônico sobre as classes subalternas em relação ao preconceito antiMezzogiorno sumamente difundido entre os proletários do norte. (KOHAN, 2007, p. 53-54).

Conforme Moraes (2002), em condições de hegemonia, a burguesia solidariza o Estado com as instituições que zelam pela reprodução dos valores sociais, conformando o que Gramsci chama de Estado ampliado, nesse caso, a Escola. Desses valores sociais reproduzidos, destaca-se o preconceito de origem e de lugar em relação aos "caipiras". Considerando os diferentes contextos geográficos e as peculiaridades culturais do Brasil, Diegues e Arruda $(2005$, p. 3) definem os "caipiras ou sitiantes": comunidades, em grande parte de meeiros e parceiros, que sobrevivem em nichos entre as monoculturas do Sudeste e do Centro-Oeste, desenvolvendo atividades agropecuárias em pequenas propriedades, destinadas à subsistência familiar e ao mercado. 
Para uma compreensão do preconceito contra os "caipiras", sugere-se a leitura de Campos (2012, 2011, 2010, 2007, 2000). O autor afirma que o processo de urbanização pelo qual passou o país procurava impor os padrões éticos e estéticos vigentes na Europa aos países então denominados "atrasados", cujos habitantes seriam portadores de uma cultura chamada de "primitiva". Em consequência, no estado de São Paulo o caipira passou a sofrer o preconceito cultural que acabou se transformando em um estereótipo. Assim, a afirmação da existência urbana se exprimiu, culturalmente, na construção de estereótipos negativos a respeito do morador rural (CAMPOS, 2012, p. 337).

Em outro texto, Campos (1997) mostra que o preconceito contra o caipira acabou se disseminando com as mudanças econômicas que ocorreram no país a partir dos anos 20. O autor aponta a mudança infraestrutural nos seguintes termos: no estado de São Paulo, com a decadência do café, o setor rural deixou de ser o que apresentava as maiores oportunidades de investimentos e o capital dos investidores passou a ser canalizado para as grandes cidades. Isso se refletiu na expansão da atividade comercial, bancária e industrial: as melhores oportunidades de remuneração do capital agora haviam se urbanizado (CAMPOS, 1997, p. 11). No plano superestrutural, a cultura sofre uma redefinição e passa a ser urbanocêntrica, o que leva a uma distinção valorativa entre o rural e o urbano.

A falácia arquitetada por Lobato [2007 (1914)] em "Velha Praga" e "Urupês" contrasta radicalmente com a profunda valorização do trabalho pelas populações "caipiras", conforme comprovaram diversos estudos, p. ex., Mariano (2011); Setubal (2005); Ribeiro, (1995); Brandão (1990); Porto (1993); Martins (1975); Candido (1971); Queiroz (1973) e Willems (1947). Para Martins (1975, p. 75), "o caipira preguiçoso estereotipado no 'Jeca Tatu' de Monteiro Lobato contrasta radicalmente com a profunda valorização do trabalho entre as populações caipiras do Alto Paraíba, nas vizinhanças da mesma região montanhosa em que Lobato trabalhou como promotor público e fixou as impressões que definiram esse personagem".

O preconceito contra a origem geográfica e de lugar foi pesquisado recentemente por Gobato (2012). A autora revelou a discriminação ao aplicar o questionário, especialmente nas respostas à pergunta: "Você já se sentiu discriminado por morar no campo?" (GOBATO, 2012, p. 92). A autora afirma que, devido à pequena amostra de dados, não é possível chegar a uma posição conclusiva. Porém é importante enfatizar que, dentre os 13 alunos entrevistados, 
6 afirmaram sofrer discriminação, isto é, praticamente a metade dos alunos sofreu com o preconceito contra a origem geográfica e de lugar (GOBATO, 2012, p. 92-93). Destaca-se a resposta do aluno sobre a pergunta em questão: "Sim, quando ia para a cidade me chamavam de caipira. Mas quase não existe mais discriminação" (ALUNO 12, 2011, p. 93, apud GOBATO, 2012, p. 93). Segundo o ponto de vista da autora desse trabalho, apesar da pequena amostra da autora, há um grande percentual de jovens que sofre com o preconceito contra a origem geográfica e de lugar no dia a dia escolar.

Conforme aponta Freitas (2007), com relação ao preconceito de origem e de lugar, a assimetria entre classes sociais, por exemplo, homens e mulheres, adultos e crianças, brancos e negros, trabalhadores urbanos e rurais, etc., para ser compreendida e analisada em profundidade, demanda um esforço contínuo no sentido de traduzir à ampla e variada sociedade brasileira, o que significa exatamente viver sob condições nas quais a desigualdade social ou a diversidade cultural têm um papel estruturante na vida de cada um.

Trabalharcom as representações sociais, especialmente a do preconceito contra os "caipiras", faz com que os alunos pensem em uma alternativa hegemônica, conforme Moraes (2002), com a qual se identifiquem, criando uma alternativa para combater o preconceito ou, pelo menos, levando-os à reflexão sobre sua situação como futuros profissionais. Para que compreendam a realidade, é necessário que falem da realidade: da realidade que vivem e da que gostariam de viver. Pensar sobre as profissões, para um adolescente, é refletir sobre o que gostaria de ser quando adulto, talvez uma oportunidade única.

\section{METODOLOGIA E ANÁLISE DOS RESULTADOS}

Para a execução do projeto de pesquisa em questão, contou-se com o apoio da chefia do Departamento de Educação, bem como da Direção do IBILCE/ UNESP, onde se desenvolveu a pesquisa. No que diz respeito aos aspectos de infraestrutura, com o apoio do Programa RENOVE da Pró-Reitoria de Pesquisa da UNESP (PROPe), que disponibilizou verba para aquisição de material permanente (Programa SPSS - Software Statistical Package for the Social Sciences), serviços de terceiros, material de consumo, bem como um bolsista no ano de implantação/ execução do projeto (maio/2012 - maio/2013). Além dessa infraestrutura, 
este projeto utilizou: (1) os Laboratórios de Informática das escolas estaduais parceiras que manifestaram interesse (Programa "Acessa São Paulo" do Governo do Estado de São Paulo) e (2) o Blog de Aula - Mutirão de Sociologia (www. mutiraodesociologia.com.br) e o Blog de Aula - Centro Virtual de Estudos e Culturas do Mundo Rural-CVECMR (www.cecmundorural.com.br), do proponente deste projeto, em que os alunos inserem comentários pertinentes ao conteúdo exposto em oficina em sala de aula. Os blogs de aula foram elaborados a partir de diversas questões desenvolvidas em: Autor (2008) e Autor (2009), como as relações entre as Novas Tecnologias, a Inteligência Coletiva e a Educação.

Esta pesquisa procura utilizar métodos qualitativos e quantitativos como estratégia de desenvolvimento da investigação. Com relação à metodologia qualitativa, foi utilizada uma "análise de conteúdo", conforme Babbie (2005, p. 70); quanto à metodologia quantitativa, foi utilizado um survey, também apresentado por Babbie (2005, p. 77), e, posteriormente, para o processamento de dados, foi utilizado o programa SPSS - Statistical Package for the Social Sciences (doravante, SPSS). O SPSS é um software (programa de computador) do tipo pacote estatístico para as ciências sociais, que inclui: aplicação analítica, data mining, text mining e estatística, que transformam os dados em informações.

O material para análise quantitativa foi coletado por meio de survey, conforme as indicações de Babbie (2005) e, posteriormente, submetido a processamento estatístico através do programa SPSS. A aplicação dos surveys vem sendo feita ao longo dos anos nos projetos desenvolvidos pelo autor (Cf. autor, 2010-2012 e autor, 2013-2015). Atualmente, conta-se com um banco de dados de aproximadamente 300 questionários. A pesquisa do tipo survey, conforme Babbie (2005), procede mediante a aplicação de um questionário com perguntas relevantes ao tema investigado. Os questionários foram aplicados por meio de entrevistas pessoais. As respostas de cada um dos indivíduos da amostra são codificadas de forma padronizada e registradas de forma quantitativa. Em seguida, os registros padronizados dos respondentes são submetidos a uma análise agregada para fornecer descrições dos indivíduos da amostra e determinar correlações entre diferentes respostas.

As conclusões descritivas e explicativas obtidas pela análise são, então, generalizadas para a população da qual a amostra foi selecionada, conforme as considerações de Babbie (2005, p. 77). Após a pesquisa do tipo survey, utilizou-se o software de análise estatística SPSS, seguindo especialmente as 
considerações de Röder (2004). O programa SPSS é um software de análise estatística, desenvolvido para o ambiente Windows e para utilização em rede, permit6indo a troca de informação com as outras aplicações do Windows, facilitando, deste modo, o processo de aprendizagem e ajuda tanto do utilizador comum do Windows como dos utilizadores mais experientes.

A seguir, abordam-se apenas alguns resultados e uma discussão sobre a pesquisa do tipo survey feita através da aplicação do questionário sobre o tema. Destacamse e comentam-se três cruzamentos de perguntas gerados pelo programa SPSS, quais sejam: 1.1 - Crosstabulation (4) Em que Ciclo e Ano você está? (52) Em casa os teus pais já te falaram sobre o preconceito de origem geográfica e de lugar (meio rural)?; 1.2 - Crosstabulation (8) Você já assistiu a situações de preconceito contra a origem geográfica e de lugar (meio rural) na sua escola? (3) Você é menino ou menina?; 1.3 - Crosstabulation (3) Você é menino ou menina? (41) Alguma vez você xingou, humilhou ou bateu em um ou uma colega devido à sua origem geográfica e de lugar (Meio Rural)? Veja-se a seguir.

Conforme se pôde observar a partir das respostas dos questionários aplicados, pouco mais da metade dos pais (54\%) fala com seus filhos adolescentes sobre preconceito contra a origem geográfica e de lugar. Esse resultado geral é sustentado mais fortemente pelas respostas dos alunos do segundo ano do terceiro ciclo, predominantemente positivas $(41,3 \%)$, do que pelas respostas dos alunos do primeiro ano do mesmo ciclo, predominantemente negativas $(17,5 \%)$. Nota-se, ainda, que essas respostas negativas do primeiro ano representam um percentual menor em relação às respostas negativas (27\%) dadas pelos alunos do segundo ano. Em parte, esses resultados são motivados pela diferença no número de respostas coletadas para cada ano letivo.

No entanto, esses resultados não deixam de sinalizar que a percepção dos alunos mais velhos sobre a temática do preconceito contra a origem geográfica e de lugar é maior. De todo modo, as taxas são relativamente baixas (próximas ou abaixo de 50\%), e se interpreta que esses resultados podem indicar certo distanciamento do tema por pais e filhos não se verem como famílias de "meio rural". Esse não reconhecimento é justamente causado pela situação de "rurbanidade" (Cf. autor; Costa, 2013), isto é, a expectativa em torno da cidade como fuga para "aplacar" os problemas do campo. Outro resultado interessante é visualizado quando há o cruzamento das respostas entre as perguntas 
Você já assistiu a situações de preconceito contra a origem geográfica e de lugar (meio rural) na sua escola?" e "(3) Você é menino ou menina?", pois permite observar a posição dos alunos ao viverem situações de preconceito contra a origem geográfica e de lugar entre seus colegas.

Conforme se pôde observar, a maioria dos alunos (84,2\%) que responderam ao questionário diz que já assistiu a situações de preconceito em ambiente escolar. Quando consideradas as respostas das meninas e dos meninos separadamente, constatou-se que as meninas são mais sensíveis a essa observação (com 54\% das respostas) do que os meninos (com 30,2\%). Essa diferença entre meninas e meninos na percepção do preconceito também se verifica nos resultados do cruzamento entre as perguntas: "você é menino ou menina?" e "alguma vez você xingou, humilhou ou bateu em um ou uma colega devido à sua origem geográfica e de lugar?".

Ao ser perguntado se o aluno já maltratou alguém por preconceito de origem, a resposta é quase unânime (92,1\%): nunca. No entanto, esse percentual se mostra mais acentuado entre meninas (58,7\%) do que entre meninos $(33,4 \%)$. Mesmo se considerado o fato de haver mais respostas das meninas no total de dados considerados, observaram-se, mais uma vez, comportamentos distintos frente a esse preconceito em relação ao gênero/sexo dos alunos, o que pode ser uma evidência da assimetria do comportamento entre gêneros na sociedade.

Contrastados os resultados de 1.1 - Crosstabulation (4) Em que Ciclo e Ano você está? (52) Em casa os teus pais já te falaram sobre o preconceito de origem geográfica e de lugar (meio rural)? e 1.2 - Crosstabulation (8) Você já assistiu a situações de preconceito contra a origem geográfica e de lugar (meio rural) na sua escola? (3) Você é menino ou menina?, verificou-se certa contradição: na Crosstabulation 1.2, os alunos, em sua maioria (84,2\%), diziam que haviam visto preconceito de origem, enquanto na Crosstabulation 1.3, esse preconceito apareceu de forma moderada (7,9\%). Haveria a percepção de bom grau de convivência? Essa contradição pode ser explicada por dois pontos de vista: o primeiro é de que os alunos não querem admitir o preconceito; o segundo é de que eles sequer percebem que estão sendo preconceituosos. A segunda hipótese, mais provável, é a que considera que a maioria das discriminações vem em forma de "brincadeira", ou seja, pode ter grande carga de maldade, mas vem lacrada por um envoltório de algo mais "leve", mais aceitável, não algo "pesado", como um xingamento preconceituoso. 
As "brincadeiras" preconceituosas, também conhecidas por bullying (Cf. Calhau, 2011), são as que mais ocorrem no meio escolar. É por meio delas que os preconceitos, em sua grande totalidade, ocorrem, quase nunca é uma coisa séria, raivosa, mais sim uma "brincadeira", algo que todos, inclusive professores e corpo de gestão e de funcionários da escola, levam na brincadeira e fazem de tudo para que a "vítima" entenda como uma brincadeira, apesar de ser dolorida e humilhante.

Do ponto de vista dos métodos qualitativos, utilizados como estratégia de desenvolvimento da investigação, isto é, a "análise de conteúdo" proposta por Babbie (2005, p. 70), destacam-se algumas postagens realizadas após as oficinas de tópicos da área de educação cooperativa. Depois da oficina, os alunos são convidados a postarem suas opiniões sobre tudo o que estiver relacionado com a aula: o trabalho, a disciplina, o professor, a escola, seus interesses, suas expectativas em relação à escola e ao seu mundo no blog de aula CVECMR (Cf. Villela, 2014-2015).

Para análise, retiram-se do blog algumas postagens dos participantes do projeto, nas quais se observa uma "prática social final" dos participantes do projeto. A ideia de uma "prática social final" remete a Saviani (1983), seguindo a didática para a pedagogia histórico-crítica, conforme Gasparin (2002). Para Saviani (1999, p. 82), a prática social inicial e final é a mesma, embora não o seja. É a mesma enquanto se constitui: "o suporte e o contexto, o pressuposto e o alvo, o fundamento e a finalidade da prática pedagógica. E não é a mesma, se considerarmos que o modo de nos situarmos em seu interior se alterou qualitativamente pela mediação da ação pedagógica". O professor e o aluno se modificaram intelectualmente e qualitativamente em relação a suas concepções sobre o conteúdo que reconstruíram, passando de um estágio de menor compreensão científica, social e histórica, a uma fase de maior clareza e compreensão, do senso comum à consciência filosófica.

As postagens exemplificam a apropriação e a reconstrução do conhecimento sistematizado, buscando evidenciar a nova postura mental do aluno frente à realidade estudada, uma nova maneira de compreender o conteúdo. Isso evidencia a prática social final, momento da ação consciente do educando na realidade em que vive. Uma etapa posterior seria propor ações concretas por ter aprendido um determinado conteúdo. Para Saviani (1983) e Gasparin (2013), é o que ele fará na vida prática, em seu cotidiano, tanto individualmente como coletivamente. Destaco o texto do aluno M. da S. A. P.: "Preconceito é ruim, porque é muito triste 
uma pessoa ficar xingando a outra porque não gostaria de receber o mesmo tratamento. Não devemos agir com preconceito". A seguir, no Quadro 1, destacamse outras postagens feitas no blog que remetem à prática social final.

\section{Quadro 1 - Postagens dos alunos sobre tópicos da área de educação cooperativa}

\section{G. R. disse:}

novembro 14, 2014 às 11:54 am

Eu gostei da aula porque falou de preconceito religioso e racial e eu não sabia sobre preconceito religioso e também falou sobre raça.

L. G. R.

\section{J. A. disse:}

novembro 14, 2014 às 11:59 am

Eu achei interessante porque falamos das diferenças das pessoas que devem ser respeitadas

e a gente tem que saber

que a gente não pode ter vergonha

do que a gente é

$:)$

J. A.

C. O. de A. disse:

novembro 14, 2014 às $12: 02 \mathrm{pm}$

Eu achei interessante porque contou de muita gente negra, branca... Se não existíssemos, o mundo não existira, pois somos muito importantes para a vida do planeta. Os primeiros habitantes do Brasil, os índios, graças a eles vieram portugueses, espanhóis, americanos. Eu não sabia que existia briga entre Coreia do Norte e do Sul e muita gente não se respeita, só querem ter preconceito e não fazer nada. Seria bom se não existisse o preconceito porque isso faz mal pra gente, impede de ter amigos.

C. O. de A.

\section{G. J. D. de P. disse:}

novembro 14, 2014 às 12:06 pm

Legal, pois aprendemos sobre o preconceito, sobre as raças. Não devemos agir com preconceito com os outros.

G. J. D. de P.

M. da S. A. P. disse:

novembro 14, 2014 às $12: 12 \mathrm{pm}$

Preconceito é ruim, porque é muito triste uma pessoa ficar xingando a outra porque não gostaria de receber o mesmo tratamento. Não devemos agir com preconceito.

M. da S. A. P.

W. S. da S. disse:

novembro 14, 2014 às $12: 17 \mathrm{pm}$

Interessante, porque fala sobre o preconceito. Não podemos julgar as pessoas como elas são de onde vem.

W. S. da S.

Fonte: Villela (2014-2015).

Na didática da pedagogia histórico-crítica, proposta por Gasparin (2013), na qual se baseou, o ponto de partida diz respeito ao nível de desenvolvimento real do educando, à prática social inicial; o segundo constitui o elo entre a prática social e a instrumentalização, isto é, a problematização; o terceiro relaciona-se às ações didático-pedagógicas para a aprendizagem, denominado instrumentalização; o 
quarto, à expressão elaborada da nova forma de entender a prática social, à catarse; e o quinto e último, ao nível de desenvolvimento atual do educando, isto é, à prática social final.

A escrita dos participantes, que se apresenta nas postagens do Quadro 1 , expressa a passagem de uma visão caótica da realidade ao conhecimento científico proporcionado pelo projeto, do qual se infere a realidade pelas novas formas de pensar. Trata-se da manifestação do aperfeiçoamento intelectual dos participantes, os quais, de forma contínua, se desafiam dialeticamente a transformar a contradição existente entre o velho (prática social inicial) e o novo (prática social final), conforme Gasparin (2013). A escrita presente nas postagens representa um dos pontos de chegada do processo pedagógico do projeto, comprovando que o processo de contra-hegemonia abre espaços de luta e deslocamentos e possibilita a reversão das formas de domínio material e imaterial (Cf. Moraes, 2002).

\section{CONCLUSÕES}

Esta pesquisa possibilitou: 1) levantar dados estatísticos sobre o preconceito contra a origem geográfica e de lugar em jovens de escolas de meio rural; 2) pensar a formação de professores sob a perspectiva da contra-hegemonia cultural; 3) inferir que os professores devem trabalhar o preconceito contra a origem geográfica e de lugar como elemento de constituição da humanização do educando; 4) comprovar que o processo de contra-hegemonia abre espaços de luta e deslocamentos e possibilita a reversão das formas de domínio material e imaterial; 5) pensar uma proposta de educação de qualidade para todos e não apenas para determinada parcela da população; 6) revelar os conflitos entre as classes sociais no Brasil; 7) contribuir para conhecer a diversidade de nossa cultura; 8 ) pensar a formação de professores na perspectiva da ação política voltada para a transformação social.

Conforme aponta Moraes (2002, p. 1), a hegemonia cultural não é uma construção monolítica, mas o resultado das medições de forças entre blocos sociais atuantes em determinado contexto histórico. O regime de hegemonia comporta espaços de luta e deslocamentos em seu próprio interior, notadamente os que se expressam nos campos cultural e comunicacional. Nessa perspectiva, 
avalia-se que as relações de poder estão atravessadas por contradições que, em maior ou menor grau, entreabrem possibilidades de reversão das formas de domínio material e imaterial.

Os professores devem trabalhar o preconceito contra a origem geográfica e de lugar em jovens de escolas de meio rural como elemento de constituição da humanização do educando e devem defender seu espaço no currículo escolar, pois é na escola que o indivíduo se apropriará desse conhecimento de forma direta e intencional, permitindo ao educando ascender do "senso comum à consciência filosófica", conforme demonstra Saviani (1983). A abordagem da temática do preconceito contra a origem geográfica e de lugar contribui para que, nesta época de acirramento de intolerâncias, se possam compreender e aceitar as diferenças, entendendo-as como produto de percursos distintos que os grupos humanos fizeram na História, conforme aponta Freitas (2007).

Partilha-se a visão de Gobato e Bezerra Neto (2010) de que há grande defasagem educacional para a população que reside em áreas rurais em relação às pessoas que residem nas áreas urbanas. Entretanto os documentos nacionais de educação possibilitam que a educação para determinado grupo leve em consideração suas especificidades culturais, políticas e regionais; desta forma, por mais que se faça necessário pensar em uma proposta de educação no campo, o ideal, em longo prazo, é que se pense em uma educação que seja de qualidade para todos e não apenas para determinada parcela da população (GOBATO; BEZERRA NETO, 2010, p. 2).

O trabalho educativo, nessa perspectiva, possibilita revelar os conflitos entre as classes sociais no Brasil, que ajudaram a criar os diversos preconceitos, e contribui para conhecer a diversidade de nossa cultura. Os projetos político-pedagógicos de grande parte das escolas do campo brasileiras reproduzem a "velha praga" arquitetada por Lobato [2007 (1914)]. De acordo com Martins (2005), "[...] é um preconceito histórico que herdamos do trabalho rural na escravidão. $O$ trabalho na roça, no tempo do cativeiro, foi amplamente depreciado porque associado à pessoa do cativo. O trabalho agrícola se tornou uma marca de inferioridade social. Os educadores incorporaram esse estereótipo [...]" (MARTINS, 2005).

A formação de professores que se defende tem como perspectiva a ação política voltada para a transformação social. A pedagogia histórico-crítica é a expressão desse caráter político, trazendo contribuições para o trabalho 
educativo, principalmente quando "problematiza" os preconceitos contra a origem geográfica e de lugar (Cf. Gasparin, 2002) e propõe uma educação que almeje superar as contradições presentes na concepção burguesa de educação. Este é o sentido de nossa contribuição para a educação socialista: desenvolver as contradições internas da escola tendo em vista a contra-hegemonia cultural, especialmente uma das representações sociais que emergem de nossa pesquisa com os alunos denominados "caipiras", repensando a teoria da hegemonia sobre as classes subalternas contemporaneamente.

\section{REFERÊNCIAS}

ALBUQUERQUE JÚNIOR, D. M. Preconceito contra a origem geográfica e de lugar: as fronteiras da discórdia. São Paulo: Cortez, 2007. (Preconceitos; v. 3).

ALMEIDA, J. L. V. Tá na rua: representações dos educadores de rua. São Paulo: Xamã, 2001.

BABBIE, E. Métodos de pesquisas de survey. Belo Horizonte: Ed. UFMG, 2005.

BRANDÃO, C. R. O trabalho de saber: cultura camponesa e escola rural. São Paulo: Editora F.T.D., 1990.

BRASIL. Decreto n 6.040, de 07 fev. Política Nacional de Desenvolvimento Sustentável dos Povos e Comunidades Tradicionais. Diário Oficial da União, Brasília, 08 fev. 2007. Disponível em: < http://www.mma.gov.br/desenvolvimento-rural/terrasind\%C3\%ADgenas,-povos-e-comunidades-tradicionais >. Acesso em: 15 maio 2013.

CAMPOS, J. T. Uma pesquisa pioneira para a compreensão da cultura caipira. Estudos Avançados (USP. Impresso), v. 26, p. 315-335, 2012.

CAMPOS, J. T. A educação do caipira: sua origem e formação. Educação \& Sociedade (Impresso), v. 32, p. 489-506, 2011.

CAMPOS, J. T. A relação entre a escola rural e a cultura caipira. Revista de Ciências Humanas (Taubaté), v. 3, p. 1, 2010.

CAMPOS JT. Festas juninas nas escolas: lições de preconceitos. Educação e Sociedade, v. 28, p. 589-606, 2007.

CAMPOS, J. T. A professora que virou caipira. Revista de Ciências Humanas (Taubaté), Taubaté - SP, v. 6, n.1, p. 43-49, 2000.

CÂNDIDO, A. Os parceiros do Rio Bonito: estudos sobre o caipira paulista e a transformação dos seus meios de vida. 2. ed. São Paulo: Duas Cidades, 1971. 
CARNEIRO, M. J. (Org.). Ruralidades contemporâneas: modos de viver e pensar o rural na sociedade brasileira. Rio de Janeiro: Mauad, 2012.

CARNEIRO, M. J. O ideal rurbano: campo e cidade no imaginário de jovens rurais. In: SILVA, F. C. T. da; SANTOS, R.; COSTA, L. F. de C. (Org.). Mundo rural e política: ensaios interdisciplinares. Rio de Janeiro: Campus, 1998.

DIEGUES, A. C. (Org.). Saberes tradicionais e biodiversidade no Brasil. Brasília: Ministério do Meio Ambiente; São Paulo: USP, 1999.

FREITAS, M. C. Apresentação da coleção preconceitos. In: ALBUQUERQUE JÚNIOR, Durval $M$. Preconceito contra a origem geográfica e de lugar: as fronteiras da discórdia. São Paulo: Cortez, 2007. (Preconceitos; v. 3).

GASPARIN, J. L. Uma didática para a Pedagogia Histórico-Crítica. Campinas: Autores Associados, 2002.

GOBATO, A. T. S. C. Educação no campo: escola do Assentamento Monte Alegre. 2012. 271 p. Dissertação (Mestrado). Programa de Pós-Graduação em Educação, Centro de Educação e Ciências Humanas, Universidade Federal de São Carlos.

GOBATO, A. T. S. C, BEZERRA, NETO L. As propostas do Movimento dos Trabalhadores Rurais Sem Terra - MST - para a educação do campo: há a necessidade de uma formação específica? Cadernos da Pedagogia. São Carlos, Ano 4 v. 4 n. 7, p. 2-21, jan -jun. 2010. Disponível em: <http://www.cadernosdapedagogia. ufscar.br/index.php/cp/article/viewFile/174/100>. Acesso em: 15 maio 2013.

GRAMSCI, A. Cadernos do cárcere. v. 1. Introdução ao estudo da filosofia. A filosofia de Benedetto Croce. 4. ed. Edição e tradução Carlos Nelson Coutinho. Coedição Luiz Sérgio Henriques e Marco Aurélio Nogueira. Rio de Janeiro: Civilização Brasileira, 2006.

GRAMSCI, A. A questão meridional. Seleção e introdução Franco de Felice e Valentino Parlato. Tradução Carlos Nelson Coutinho e Marco Aurélio Nogueira. Rio de Janeiro: Paz e Terra, 1987.

KOHAN, N. Gramsci e Marx: hegemonia e poder na teoria marxista. Tempos Históricos (EDUNIOESTE), v. 10, p. 15-70, 2007. Publicado originalmente em La Izquierda Debate. 17 de março de 2001. Tradução de Edmundo Fernandes Dias.

LEFEBVRE, H. La presencia y la ausência. Contribución a la teoría de las representaciones. Trad. Óscar Barahona y Uxoa Doyhamboure. México: FCE, [1980 (2006)].

LOPES, W. J. F. As representações sociais dos jovens do campo acerca de suas escolas. 2008. 145p. Dissertação (Mestrado em Educação). Instituto de Educação, Universidade Federal do Pará.

LOWY, M. Redenção e utopia: o judaísmo libertário na Europa central. São Paulo: Companhia das Letras, 1989. 
LUTFI, E. P.; SOCHACZEWSKI, S.; JAHNEL, T. C. As representações e o possível. In: MARTINS, José de Souza (Org.). Henri Lefebvre e o retorno à dialética. São Paulo: Hucitec, 1996.

MARIANO, N. F. Fogão de lenha, chapéu de palha: As manifestações da cultura caipira em Jaú (SP). Jundiaí: Paco Editorial, 2011.

MARTINS, J. S. A educação rural e o desenraizamento do educador. In: Revista Espaço Acadêmico, número 49, Junho de 2005. Disponível em: <http://www. espacoacademico.com.br/049/49cmartins.htm>. Acesso em: 15 maio 2013.

MARTINS, J. S. Capitalismo e tradicionalismo. Estudos sobre as contradições da sociedade agrária no Brasil. São Paulo: Livraria Pioneira Editora, 1975.

MORAES, D. Imaginário social e hegemonia cultural. Net, Rio de Janeiro, 2002. Disponível em: < http://www.acessa.com/gramsci/?page=visualizar\&id=297 >. Acesso em 12 fev. 2013.

PORTO, M. R. S. Escola rural: cultura e imaginário. 1993. 194 f. Tese (Doutorado em Educação) - Faculdade de Educação, Universidade de São Paulo, São Paulo.

QUEIROZ, M. I. P. Bairros rurais paulistas: dinâmica das relações bairro rural-cidade. São Paulo: Duas cidades, 1973.

RIBEIRO, D. O povo brasileiro. A formação e o sentido do Brasil. São Paulo: Companhia das Letras, 1995.

RÖDER, K. Análise da pobreza com SPSS: manual do curso. Net, Beira, Moçambique, 2004. Disponível em: <http://www.klaus-roeder.com/Ordner/DocumentsWork/ Training/PobrezaSPSS041221.pdf> . Acesso em 10 fev. 2012.

SAVIANI, D. Educação socialista, pedagogia histórico-crítica e os desafios da sociedade de classes. In: SAVIANI, Demerval; LOMBARDI, Claudinei. (Orgs.). Marxismo e Educação: debates contemporâneos. São Paulo: Autores Associados, 2005.

SAVIANI, D. Educação: do senso comum à consciência filosófica. 3. ed. São Paulo: Cortez, 1983.

SEE-SP. Proposta curricular São Paulo faz escola. Portal da Secretaria de Estado de Educação do Estado de São Paulo. Net, São Paulo, 2012. Disponível em: < http:// www.saopaulofazescola.sp.gov.br>. Acesso em 12 fev. 2012.

SETUBAL, M. A. Vivências caipiras: pluralidade cultural e diferentes temporalidades na terra paulista. São Paulo: CENPEC: Imprensa Oficial do Estado de São Paulo, 2005.

SILVA, R. P. R. P. Quando eu for grande quero ser... O trabalho para as crianças de meio rural: com as mãos na terra e os olhos no futuro. 2006. 215f. Dissertação (Mestrado). Instituto de Estudos da Criança, Universidade do Minho, Portugal. 
VILLELA, F. F. Centro virtual de estudos e culturas do mundo rural (CVECMR). 2014-2015. (Projeto de Ensino). Net, São José do Rio Preto - SP, 2014-2015. Disponível em: < http://www.cecmundorural.com.br/ >. Acesso em 01 mar. 2014.

VILLELA, F. F. Novas ruralidades e mundo do trabalho: estudo das representações sociais de jovens de escolas de meio rural através do uso de mídias sociais. 2013-2015. (Projeto de Pesquisa do Plano Global de Atividades). Departamento de Educação, Instituto de Biociências, Letras e Ciências Exatas, Universidade Estadual Paulista, São José do Rio Preto.

VILLELA, F. F.; COSTA, F. S. Ruralidades contemporâneas em São José do Rio Preto SP: estudo dos modos de viver e pensar o rural através do uso de mídias sociais In: III Encontro Núcleos de Ensino \& II Encontro PIBID da Unesp, 2012a, Águas de Lindóia - SP. Anais do III Encontro Núcleos de Ensino \& II Encontro PIBID da Unesp. São Paulo - SP: Unesp, 2012a.

VILLELA, F. F. A formação de intelectuais e a organização do trabalho pedagógico nas escolas do campo. 2010-2012. (Projeto de Pesquisa do Plano Global de Atividades). Departamento de Educação, Instituto de Biociências, Letras e Ciências Exatas, Universidade Estadual Paulista, São José do Rio Preto.

VILLELA, F. F. Mutirão de sociologia - blog de aula. 2011. (Projeto de Extensão). Um filme rodado no distrito de Talhado de São José do Rio Preto - SP - Brasil: João de Barro de Raffaele Rossi (1970). Disponível em <http://www.mutiraodesociologia.com. $\mathrm{br} / ? \mathrm{p}=841>$. Acesso em: 25 jun. 2011.

VILLELA, F. F. A escola da justiça global. 2009. Supervisão: Profa. Dra . Liliana Rolfsen Petrilli Segnini. Monografia (Pós-Doutorado). Faculdade de Educação, Universidade Estadual de Campinas.

WILLEMS, E. Cunha: tradição e transição em uma cultura rural do Brasil. São Paulo: Secretaria da Agricultura do Estado de São Paulo, 1947.

Artigo recebido em: 17/06/2015

Aprovado em: 09/10/2015

\section{Endereço para correspondência:}

Fábio Fernandes Villela. Unesp, Instituto de Biociências Letras e Ciências Exatas de São José do Rio Preto - Ibilce, Departamento de Educação, Rua Cristovão Colombo, 2265, Ala 4, Sala 3, Jardim Nazareth, São Jose do Rio Preto, SP, CEP: 15054-000. E-mail: fvillela@ibilce.unesp.br. 